\title{
LUT
}

University

\section{Individual Conditions for Co-production of a Social Innovation in a Living Lab: Case Sunshine PopUp Park}

Henttonen Kaisa, Nisula Anna-Maija, Blomqvist Kirsimarja, Horila Anne, Takala Minna

This is a Author's accepted manuscript (AAM) version of a publication

published by Springer

in Lehtimäki, H., Uusikylä, P., Smedlund, A. (eds) Society as an Interaction Space. Translational Systems Sciences, vol 22

DOI: 10.1007/978-981-15-0069-5_14

Copyright of the original publication: (c) Springer Nature 2020

Please cite the publication as follows:

Henttonen, K., Nisula, A.M., Blomqvist, K., Horila, A., Takala, M. (2020). Individual Conditions for Co-production of a Social Innovation in a Living Lab: Case Sunshine PopUp Park. In: Lehtimäki, H., Uusikylä, P., Smedlund, A. (eds) Society as an Interaction Space. Translational Systems Sciences, vol 22. Springer, Singapore. pp. 293-310. DOI: 10.1007/978-981-15-0069-5_14

This is a parallel published version of an original publication. This version can differ from the original published article. 


\title{
Individual conditions for co-production of a social innovation in a Living Lab -Case Sunshine PopUp Park
}

\author{
Kaisa Henttonen \\ University of Eastern Finland, Finland \\ Anna-Maija Nisula \\ LUT University, Finland \\ Kirsimarja Blomqvist \\ LUT University, Finland \\ Anne Horila \\ Growth Corridor Finland, City of Hämeenlinna, Finland \\ Minna Takala \\ Regional Council of Häme, Finland
}

Correspondence on this article should be referred to Kaisa Henttonen, Business School, University of Eastern Finland, Microkatu 1, 70150 Kuopio, Finland. Email kaisa.henttonen@uef.fi

Cite this chapter as: Henttonen K., Nisula AM., Blomqvist K., Horila A., Takala M. (2020) Individual Conditions for Co-production of a Social Innovation in a Living Lab: Case Sunshine PopUp Park. In: Lehtimäki H., Uusikylä P., Smedlund A. (eds) Society as an Interaction Space. Translational Systems Sciences, vol 22. Springer, Singapore

\begin{abstract}
Participative processes and the empowerment of citizens are seen as central aspects of social innovation, which involves collaborative activities between the private, public and third sectors. It is important to identify the factors influencing citizen involvement, and we therefore investigate how people can be encouraged to contribute to improving societal well-being and to enhance partnerships between citizens, regions and also the profit and non-profit sectors. In particular, we investigate the motivation of citizens involved in the co-production of social innovation. We also provide descriptions of specific citizen- and public authority-related outcomes of the co-production process, which are missing from most previous studies (Voorberg, Bekkers, \& Tummers, 2015). We also identify actions that might facilitate the coproduction of social innovation. In this study, we report a successful case of co-produced social innovation and derive findings from it.
\end{abstract}

Keywords: co-production, citizens involvement, non-profit, profit organisations, urban Living Lab, motivation, value, best practices 


\title{
Individual conditions for co-production of a social innovation in a Living Lab -
}

\author{
Case Sunshine PopUp Park
}

Participative processes and the empowerment of citizens are seen as central aspects of social innovation that involve collaborative activities among the private, public and third sectors. The involvement of users (here citizens) and collaborative partnerships with the private, public and third sectors, also called fourth-sector activity can reduce public expenditure and contribute positively to quality of life and sustainable development via suitable public policy. Empowerment and collaboration can bolster social, economic, environmental and cultural outcomes and models of place-based innovation. Therefore, it is important to identify the factors influencing citizen involvement (e.g. Dutilleul, Birrer and Mensink, 2010), so as to empower and connect various stakeholders creating a fruitful environment for social innovation. In this paper, social innovation refers to 'the process of collective idea generation, selection and implementation by people who participate collaboratively to meet social challenges' (Dawson \& Daniel, 2010, p. 16).

Living labs, on the other hand, are seen as spaces facilitating social innovation. They have been characterised as a methodology that highlights user involvement in innovation. The application of living labs to real-life settings and 'real' experimentation started in Europe around the year 2005 and was based on Nordic countries' experience of involving users. Cunningham, Herselman, and Cunningham (2012) defined the living lab as an environment, a methodology or an approach that facilitates user-driven open innovation within real-life rural and urban settings/communities in which users collaborate with multiple committed stakeholders (non-governmental organisations, small and medium-sized firms, industry, academic/research institutes, governments or donors) in one or more locations to become cocreators or co-designers of innovative ideas, processes or products within multidisciplinary environments. Successful collaboration may result in improved processes or services and new business models alongside social innovations (rules, procedures, programmes and norms) that can be replicated to improve the overall quality of life and the socioeconomic conditions through involvement in communities. In this study, a living lab is seen as a functional place in a real-life context that enables public-private partnerships among individuals (entrepreneurs and citizens), enterprises, public entities and universities. The real-life context in our case is a small, pioneering Finnish town called Hämeenlinna and its surroundings, where citizens took 
over a public place and turned it into an oasis for all the citizens in town. It became a social space for innovation - a place by citizens for citizens that supported connectivity and social action among citizens. Overall, interest in the potential of citizen involvement is growing among cities and scholars (Wascher, Habel, Schrot \& Schultze, 2018), and several attempts to foster involvement of citizens have been made. For instance, the URBACT program — funded by the European Commission Regional Development Fund (ERDF) — targeted the promotion of social innovations (Urbact, 2015), highlighting sufficient environment and spaces of experimentation as central for social innovation. However, while most municipally originated social innovation labs are funded experimental projects with a specific theme around which the actors are gathered, in the case of the present study, the idea for social innovation originated from citizens, and it gathered volunteer citizens, firms and public actors to co-produce social innovation without allocated budgets or formal project organisation. Hence, the case of the present study is unique, as it employs citizen potential starting from the initial steps of social innovation. In addition, the present study sheds light on citizen involvement in small cities, which often tend to ignore the potential of citizen initiatives, likely due to a lack of knowledge, skills or sufficient mechanisms to employ the potential of citizens for innovative solutions. Hence, living labs, as seen in our case study example, are mechanisms for stimulating connectivity among citizens (Dutilleul et al., 2010) and enabling 'scaffolding' efforts and intermediation for structuring and managing people involved in co-production in the innovation process (Moulaert \& Mehmood, 2010).

Co-production is defined in this study as 'the mix of activities that both public service agents and citizens contribute to the provision of public services' (Ostrom, 1999). Coproduction differs from classic volunteerism in that it concerns services the volunteers also use themselves (Voorberg et al., 2015). Co-production is used here interchangeably with the related concept of co-creation; we assume an interactive and dynamic relationship in which value is created from interaction. (Osborne, 2018; see also Brandsen and Honigh on the different types of co-production)

Most previous studies in the field of co-production and social innovation have focused on citizens as co-implementers, while only a few focus on the citizens' degree of involvement as co-designers or co-initiators (Voorberg, Bekkers, \& Tummers, 2015). First, there is a need to directly address the citizen involvement in the co-production of social innovation. Second, because the stakeholder in co-production is acting in a setting where users and organisations are likely to have contradictory role expectations, it is useful to research the relation between the diversity in roles and the outcomes of co-production processes. Third, it is important to 
understand under what conditions citizen involvement in the co-production of social innovations can be linked to more positive, concrete and functional outcomes. Only a few prior studies expressly analyse such outcomes (see review by Voorberg et al., 2015). In this chapter, we focus on the problem of how people can be encouraged to contribute to improving societal well-being and enhancing partnerships between citizens, regions and the profit and non-profit sectors. This is an important question, because co-production can help make the best use of resources, deliver better outcomes for people who use services, build stronger communities and develop good citizenship. It also seems to point out a paradigm shift, in which the consideration of citizens as passive consumers of public services has moved towards a view of citizens as coproducers (Voorberg et al., 2017). In this chapter we specifically investigate which individual conditions foster citizen involvement in co-production of social innovations. This involves analysing the types of people involved and their motives. The analysis is supported by addressing the questions: What motivates citizens to take part in co-production of social innovation? What value does co-production of social innovation create for the citizens, entrepreneurs and public authorities involved? What are the best practices to foster coproduction of social innovation? Do the motivations, perceptions of value and best practices differ according to the degree of involvement (e.g. co-implementer, co-designer or co-initiator) people have in co-production?

Our study results reveal influential factors on the organisational and citizen side of coproduction in different degrees of involvement. Furthermore, we also describe specific shareholder-related outcomes of the co-production process absent from most of the previous studies (Voorberg et al., 2015). Finally, we identify actions that can be taken to overcome potential barriers to the co-production of social innovations.

The remainder of the chapter is structured as follows. In the literature review, we discuss which individual conditions foster citizen involvement in co-creating social innovations. This involves themes such as citizen involvement motivation, value gained through involvement, enhancing conditions and best practices for co-production. In the methodology section, we will present the case study design and provide details on qualitative data collection and qualitative content analysis. The results section of the study reviews the motivations, values and coproduction best practices in each degree of involvement investigated: co-implementer, codesigner and co-initiator. We also suggest some new degrees of involvement and motivations not present in earlier research. In the final section, we will present conclusions and notes on the limitations of the study. 


\section{Individual conditions fostering people's involvement in co-production social innovations}

In this study we focus, following Voorberg et al., (2015), on three types of citizen involvement, as we are interested in determining whether the motivations, perception of value and best practices differ according to the degree of involvement (co-implementer, co-designer, or coinitiator) people have in co-production. The first type of citizen involvement sees the citizen as co-implementer of public services; the citizen performs some implementation tasks. The second type represents the citizen as co-designer. Often, the initiative comes from the public organisation, but citizens decide how the service delivery process is being designed. The third type presents the citizen as an initiator and the government is seen as an actor that follows.

Next, we turn our attention to what we know about the supporting questions of the analysis in this study. These are: what motivates individuals to take part in co-production of social innovation? What value co-production of social innovation creates for the various parties involved? What the best practices are to foster co-production?

\section{Motivation}

There is a considerable volume of literature on the factors that motivate citizens and other types of volunteers to offer public service, regardless of the fact that we do not know whether the motives of citizens and other volunteers differ according to their degrees of involvement. In her pioneering work, Sharp (1979) studied citizens' motivations in the context of crime prevention, and, as a result, devised a typology of incentives for participant involvement consisting of three parts (based on Wilson, 1973). The typology included material incentives (money, goods and services), solidary incentives (socialising, a sense of group membership, being well regarded, fun, etc.) and expressive incentives (e.g. environmental conservation and supporting the needy). Sharp's (1979) study found the effectiveness of motivation depends of the form of co-production. Individualistic forms of co-production emerge from more material and solidary interests, whereas collective action (e.g. block watches or neighbourhood watch initiatives) emerges from solidary interests and not from material interests.

Prior research on volunteer motivations, in contrast, identifies six categories of motivation (e.g. Clary, Snyder, \& Stukas, 1996; Clary, Snyder, Ridge, Copeland, Stukas, Haugen, \& Miene, 1998). These are: 1) values (people's willingness to express humanitarian values or to be altruistic), 2) understanding (when people view volunteer work as an opportunity to gain new knowledge of the world and develop their skills), 3) enhancement 
(when people develop psychologically and improve their self-esteem), 4) career (people volunteering to gain experience to benefit their careers, 5) social (people wanting to be part of or involved with social groups of importance to them), and 6) protective (when people volunteer to aid others' efforts to cope with their own anxieties and conflicts). Of these six functions, values were found to be most important motivation followed by the enhancement, social and understanding forms. The career and protective forms of motivation were found to be the least important (Clary et al., 1996). To summarise, we can identify four possible sources of motivation for co-production: material rewards, solidarity, values and intrinsic rewards.

\section{Value gained by citizen involvement in co-production}

The value of citizen involvement can be a result of involvement in the co-production or of the outcome of co-production or both. Most relevant academic studies have focused on the factors influencing the co-production process, but only a few studies have investigated co-production outcomes (Voorberg et al., 2015). Previous research has found, for example, that in coproduction of health care for hospital clinic patients, the outcome - treatment quality improved (Leone, Walker, Curry \& Agee, 2012). Other research establishes that it is easier to acquire knowledge on how to organise and maintain organic farming when the initiative involves farmers working in organic farming (Baars, 2011). There are also previous studies reporting no improvement related to outcomes through co-production. For example, Benari's (1990) study reports how co-production in the context of garbage disposal in Japan failed because people did not separate their garbage as instructed. In addition, Meijer (2011) found that co-production is not necessarily a source of better neighbourhood safety. To summarise, previous research suggests that the concrete outcomes of co-production have mostly been an increase (or reduction) in effectiveness. Additionally, previous studies report contradictory results related to the effectiveness of co-production.

\section{Facilitating co-production}

We examine how to facilitate co-creation, as it seems that there is little specific literature on co-production, and in addition, the two concepts seem to be very closely interlinked (Voorberg et al., 2015). According to the review, both literature streams identify citizens as valuable partners in the delivery of public services. In addition, emergent and multiparty co-production research describes co-production in an open and public living lab space for social innovation.

Prior research suggests that collaborative emergence (co-production) is likely to occur 
under particular types of conditions that also reflect the circumstances of an open living lab space. Scholars such as Sawyer and DeZutter (2009), Gray (1989), and Prins (2006) present equal characteristics that enable collaborative emergence: 1) interdependence of actors/stakeholders, 2) openness to unfolding interaction, 3) openness towards outcome/solution, 4) equal participation and engagement of actors and 5) collective responsibility and shared leadership of the future direction of the task (or the goal of the event). However, the nature of co-production varies in terms of environment (the people involved, access, the goal of the co-production (task), time and the organisation of the process) and the degree of co-production (ranging from self-organised co-production to a managed form).

The process of co-production is more experimental and iterative than it is pre-planned, a fact related to the openness towards emerging interaction and the direction of the solution. As a result, the development evolves and thrives amidst the dynamic interaction between the involved members (e.g. John-Steiner, 2000), who feel themselves to be responsible and empowered participants in the co-production event. It follows that equal involvement and empowerment of the people involved are critical for successful co-production. Informal communication and a light-hearted environment encourage participants to express their ideas, to help other involved participants, to contribute ideas and to build on the ideas of the others; these aspects also facilitate theoretical and practical experiments. Non-hierarchical interaction is typical of co-production activity, which is related to shared leadership and decision-making practices. This means that leadership is given and taken according to the situation, and that decision-making and direction setting are collectively stated and redefined in the course of the process. In addition, in order to build a shared vision and a future direction of the process, practices capable of recognising and making visible the diverse goals of the people involved are required. The space and facilitation of the co-production process are critical for coproduction. The enabling and flexible space (either physical/virtual or mental) support coproduction, whereas facilitation is often required in both supporting interaction and relationships between participating members, as well as in directing and structuring the course of the co-production (in terms of the content and process).

To summarise, the previous research on emergent collaboration and co-production describes the conditions under which multiparty co-production is likely to occur. It also indicates that successful co-production is highly dependent on the dynamics and interaction between the members involved, which can be supported by facilitation. 


\section{Methodology}

Our theoretical orientation and related methodological approach can be described as theory elaboration (Ketokivi \& Choi, 2014). We build on past research on co-production of social innovations yet remain open to the idiosyncrasies in the case's context. In the following, we adopt interpretative sensemaking approach to first illustrate and then theorise based on the specific case context (Welch, Piekkari, Plakoyiannaki and Paavilainen-Mantymaki, 2011).

\section{Case Sunshine PopUp Park}

Nowadays, cities struggle with empty malls and other business spaces, and they appraise novel reuse ideas for such abandoned spaces. The small Finnish city, Hämeenlinna, took the initial steps to involve citizens in the collective building of their city. The Sunshine PopUp Park was an experimental in-house park in a local mall, the concept for which arose via an idea competition. The idea of a group of students at a local upper secondary school, the Hämeenlinna Lyseo, was selected to be implemented on a voluntary basis in collaboration with regional development experts. The original idea behind and aim of the experiment was to create an experimental Sunshine PopUp Park in a local empty mall to bring light and life into the city centre. The park created a green oasis and open meeting place for all ages and was therefore named the Sunshine PopUp Park.

The Sunshine PopUp Park was experimental in nature. It was created according to open innovation principles emphasising open citizen involvement and co-production. The city rented the space from the empty mall for the Sunshine PopUp Park for a test period (three months). The indoor park was constructed by volunteers and was developed continuously based on original ideas and ideas offered by volunteers and visitors. The volunteers were mainly citizens, representatives of public authorities and local entrepreneurs, but everybody was welcome. In addition to building a space, the volunteers organised social activities and events for citizens in the space. Events organised by a variety of volunteers at the Sunshine PopUp Park included start-up events for companies, information on gardening and fruit tree maintenance, entrepreneurship training sessions, a Valentine's Day event, an Easter event, a flea market, recycling workshops, education and research information events, expert lectures, a bioeconomy afternoon, national general election themed events and city meetings targeted at young people and the elderly. Additionally, there was an exhibition of indoor graffiti, watercolour paintings, musical performances and dancing. 
What is more, students from educational institutions of all levels, from kindergarten to university, supported the activities. Teachers and a student counsellor also played an important role in guiding the students. Furthermore, the involvement of the members of the regional LUO cooperation network, in the field of natural resources, helped, especially when communicating the opportunity to get involved with the Sunshine PopUp Park project. LUO (Luonnonvaraalan verkosto) is a cooperation network in the field of natural resources in the Kanta-Häme region in southern Finland. The network's main aims are to increase research and development cooperation, use learning spaces together and discover innovations in the field of bio-economy and natural resources.

There was little in the way of monetary resources available, and the Sunshine PopUp Park aimed to operate by borrowing things, using recycled materials and using solicited donations. The use of social media was an important element in communication and coordination. The experiment was successful, and results included attracting over 11,000 visits to the park, hosting around 30 workshops and events, assembling a team of around 100 volunteers and trainees, obtaining the support of around 30 firms and gathering around 250 ideas and recommendations. The advent of the Sunshine PopUp Park prompted around ten newspaper articles and five television segments. The park was opened on 16 January 2015 and closed on 18 April 2015, when the experiment ended. Visitors to the park spanned all age groups from infants to the elderly. The majority of visitors came from Hämeenlinna, but there were also visitors from around the world from Africa to Alaska.

\section{Data collection}

The urban living lab case Sunshine PopUp Park was chosen because we were interested in understanding this unique case (Stake, 2005). Our case was a successful experiment that attempted to involve citizens in the ideation and implementation of social innovation. Despite the living labs, whose purpose is social innovation, being initiated by the European Union, with funding from the ERDF, there is a scarcity of research and practical understanding of the living labs based on citizens' ideas and volunteer involvement of citizens, firms and public actors. For us, this specific case provided a situationally grounded opportunity to understand contextual idiosyncrasies (Ketokivi \& Choi, 2014), as our underlying question was to determine what made this active, citizen-volunteer co-production successful. The ten informants of this study were selected from different stakeholder groups to gain a holistic view 
of the phenomenon. The groups were students, teachers, entrepreneurs, citizens and representatives of public authorities.

The interview questions concerned Sunshine PopUp Park's development since its foundation. We were interested in learning of the actors' subjective experiences and the interviewees were asked to describe their backgrounds and their tasks within the Sunshine PopUp Park project to ensure that they had had direct experience with the studied phenomenon. They were also asked to describe what motivated them to get involved, how they had benefited from getting involved and also what they perceived as the best practices regarding coproduction based on their Sunshine PopUp Park experiences.

The interviews were conversational and lasted between half an hour and one hour. Each interviewee was made aware of the aim of the research. Beyond that, the interviewees were encouraged to talk about their experiences in their own words. The questions were repeated if necessary, and iterative and circular questioning and discussion were allowed. Furthermore, the information received was continually clarified and verified during the interview. All interviews were recorded and transcribed, and, in addition, the researchers took notes. All individual interviewees were guaranteed their responses would remain confidential.

\section{Data analysis}

We conducted a deductive analysis by performing a literature review on motivations, on value gained by the citizens involved and on best practices for co-production. Theory driven template analysis (King, 2004) was undertaken to categorise motivations, value and best practices identified in the data. A qualitative content analysis was then used to systematically code the interview data with categories identified in the literature review. During the coding stage, researchers sought theory-driven categories in the interview data, and identified were excerpts that described the motivations, value gained by the citizens and best practices for coproduction. The first round of analysis focused on each citizen separately. Thereafter, a crosscitizen group analysis was conducted to gain a more holistic understanding of the phenomenon and to compare and synthesise the findings. Data reduction and classification processes were used to find patterns in the data and to define categories (Gummesson, 2005). The results of the analysis are reported in Table 1 (see Appendix 1). 


\section{Results}

The results from the interviews indicate that citizens/volunteers are motivated to participate by self-interest, as none of the citizens/volunteers (co-implementer, co-designer, co-initiator, and public authority) were motivated by material rewards to co-produce something that could not be clearly defined beforehand (as the Sunshine PopUp Park experiment was); thus, it seems that volunteering citizens are not benefit maximisers, who only co-produce when benefits outweigh costs. However, regardless of the fact that a self-interest motivation has its limitations, some of the citizens/volunteers were motivated by non-material rewards, that is, their desire to boost their own business, aspirations related to their own careers, and carrying out regional developmental plans. This was typical of those as a co-designers and a public authority role. One of them said, 'Yes, I thought I could do my work there and maybe market my work'.

The study results indicate that also social identification with others was one of the motivations of co-production, that is, people were motivated by group affiliation and belonging. They wanted to be associated with and to interact with other people, and to gain their approval. One of the volunteers stated: 'This was a way of getting to know people with similar interests. They also had skills and knowledge that interested me.' Another motivation was the expressive values of citizens/volunteers, which reflected purposive norms and commitment to social issues, that is, environmental issues. To summarise, citizens/volunteers are ready to contribute time and effort to experiments like the Sunshine PopUp Park, if they do it for their own reasons. These reasons are far more complex, than just money or other material rewards.

So that co-production would not be considered a value itself - as it is been in many previous studies - we also investigated whether the citizens had found their involvement in coproduction beneficial. Increasing effectiveness in terms of information diffusion throughout society and finding new potential clients faster were important benefits to those being coimplementers and co-designers and for those in the public authority role. One co-designer stated: 'Other citizens came to ask for advice and there were also some business cases, for 
example, someone needed to have their apple trees cut, and such like'. Additionally, one of the public authority representatives said: I think the value I gained was that I realised that there is a need for this type of space, and that this idea can be multiplied, and also there can be many different types of activity. The idea also was that people from some other cities could visit the park and see whether they could do something similar.

Other outcomes reported were; getting a good feeling when doing something and making other people happy, strengthening social cohesion; getting new contacts; and increasing public awareness of one's own business. To summarise, the outcomes of co-production did not only relate to gaining more effectiveness or efficiency. Finally, we investigated the conditions under which co-production and, more specifically, successful co-production as in the Sunshine PopUp Park case took place. More specifically, we investigated the best practices for successfully managing co-production. Technology is able to enhance co-production in that it can provide opportunities for dispersed action and it can make co-production more social. In the study case, social media (in the form of a closed Facebook group) was used to provide ongoing documentation and enable coordination. This created the (social) infrastructure for open interaction between all the citizens. There was also a notebook provided at the Sunshine PopUp Park itself to enable citizens in co-production to write down events that happened during the day (with visitors etc.) and potential problems. The citizens had also jointly set what could be called house rules and all new citizens in co-production were informed of those rules, which were visible on the wall at the project. The house rules concerned various issues including opening and closing hours and the rules were designed around the principle of DIT, that is, do it together. All citizens were encouraged to be open to all outcomes or solutions and all ideas were welcomed at any time during the experiment. However, as one of the public authority representatives stated: I had to make sure that all ideas that were to be carried out, were within the scope of the experiment; for example, there were suggestions to bring in a knitting machine or ideas that required a lot of resources like painting the whole place or installing a new floor...these types of ideas were not implemented. However, you cannot have too strong a vision, because it will restrict the experiment...And you have to tolerate things not necessarily being perfect right away and also encourage others to cope with it. If some materials et cetera were needed, then you just had to figure out where to get them. The idea was that we did not have funding for this experiment.

Equal involvement and engagement of actors was further influenced by the willingness of public authorities to support co-production. This was done, for example, by acting as a role model, through active involvement, and by encouraging everyone to provide ideas: You had to 
also make people realise that it is not just their role to create ideas and then we (the public organisation representatives) would carry them out. The idea is that you do things yourself too.

The citizens/volunteers had a collective responsibility for the experiment and thus shared the leadership of it. One of the co-initiators explained: I think it worked so well because everyone was a volunteer, and no one could complain because no one was paid...In volunteer work everyone can put in the effort they want to.

Hence, the experiment was just as good as the citizens as volunteers co-produced intended it to be. Material rewards, on the other hand were not significant, although coffee was offered to the volunteers. Finally, our study findings show that citizen/volunteer's characteristics also seem to determine whether they are willing to get involved. Personal traits such as openness and being easy going were mentioned. To summarise, it is important to understand that citizen involvement is not just about facilitating citizen involvement and developing managerial practices to motivate them. It is a complex combination of individual motivation, the benefits produced for individuals (value) and enabling circumstances and involvement. Citizens/volunteers need to be motivated to engage in co-production, but also effort is required to overcome the hurdles of citizen involvement.

\section{Discussion}

Below we discuss the results relating to our research questions and the previous studies, and thereby shed light on co-production of social innovations in the context of public experiments and spaces to increase citizen active involvement. First, we asked under which individual conditions do people co-produce social innovations. The question required that we understood the degree of citizen involvement and their motives for getting involved. We also investigated whether individual motivational conditions differ according to the degree of citizen involvement (co-implementer, co-designer, or citizen initiator).

Past research has recorded the presence of enhancement motivation (e.g. Clary et al., 1996), and that was also visible in our results, as some citizens learned about themselves and were able to improve their esteem through the self-actualisation process. Career motivation was also part of the motivation through learning, new contacts, and even potential customer relationships. Likewise, social motivation was important for a variety of citizens, from those new to the town to those accustomed to working alone. However, the respondents did not openly express the protective form of motivation, but it could have been seen as a preventive 
idea for the Living Lab as a mechanism to combat the dark winter months and the associated low moods and seasonal affective disorder.

Regarding the motivations of citizens of various degrees of involvement, the current research aligns with that of Voorberg et al. (2015) in indicating that citizens as co-designers had both intrinsic and extrinsic motivations. Their extrinsic motivations were related to boosting their own business or career, whereas their intrinsic motivations were related to seeing how public spaces could be used for similar purposes. The distinction between the extrinsic and intrinsic motivations was not very clear, and as were others, they were also motivated by solidarity. Motivational synergy (e.g. Grant, 2008) may explain this. The motivation of the citizen initiator was purely intrinsic, the person being driven by a vision and seeing the experiment realised. In addition to the degrees of involvement identified by earlier research, we also identified the critical roles of public authorities, whose involvement was based on intrinsic rewards and who then used the experiment as a means to advance a regional development plan. There were some differences between the degrees of involvement by the citizens in terms of individual intrinsic rewards. Some citizens, especially those being codesigners, were motivated by non-material rewards, such as their boosting own business, their own career, or progressing regional plans. However, the degrees of involvement and motivations are not clear-cut; the co-initiator also actively got involved in every phase of the design and implementation of the experiment. Likewise, the citizens as a co-designers got involved in the implementation. It is therefore not possible to distinguish pure degrees of involvement in this type of emergent and open-ended experiment, the degrees of involvement identified are more like dominant degrees of involvement that differentiate citizens at a certain time, and complementary degrees of involvement supporting the collective effort, yet citizens degree of involvement is less significant and the related effort invested into them less. There were also some signs of role competition, when two people identified themselves as coinitiators. To answer the question of what motivates citizens to get involved in the coproduction of social innovation, we found that material rewards are not the main motivators but instead the key drivers of involvement are solidary and expressive incentives and individual intrinsic motivation. Hence, the people who find social relationships (connectivity) valuable both for collective and individual development are motivated to get involved in social innovation events.

Secondly, we also asked what value co-production of social innovation creates for the various parties involved. The findings of our study support previous studies that identified material, solidary and expressive incentives, of which the solidary incentives were found to 
drive the involvement in the collective forms of co-production (Sharp 1979). Another identified value was the expressive incentives of citizens. These took the form of purposive norms and commitments relating to social issues, which in this case meant environmental issues. Material incentives did not drive citizen involvement in the co-production of social innovation in our case, and were secondary to the impact of solidary and expressive incentives (Sharp, 1979; Voorberg, Jilke, Tummers \& Bekkers, 2018). Interestingly, almost all of the interviewed citizens had some experience in volunteer work, which speaks of their value-based involvement. Citizens value-based involvement manifested, for example, in a willingness to co-create a place for elderly retired people to experience the shrubbery and trees, or a meeting place for young mothers. Many of the citizens stated that they get involved to learn about an interesting experiment, and had found they learned about themselves and others. The citizens also reported that the positive social interaction made the learning experience empowering. They also learned social and entrepreneurial skills, such as those required to organise events.

Thirdly, we investigated what are the best practices to foster co-production of a social innovation? The process of co-production and co-implementation of the Sunshine PopUp Park was more iterative than pre-planned as it developed by planning and experimenting via contributions from the volunteers. Hence, it equates to the literature on emergent collaborative (Prins, 2006), living labs (Moulaert \& Mehmood, 2010; Cunningham, Herselman \& Cunningham, 2012; Dutilleul et al., 2010). With regard to factors influencing successful coproduction in an open public Living Lab, our results show that the characteristics of emergent co-production identified in previous studies (Sawyer and DeZutter, 2009; Gray, 1989; Prins, 2006; John-Steiner, 2000) were also identifiable in the Sunshine PopUp Park case. In the case of a Living Lab, the open access aspect is catered for by voluntary and egalitarian involvement; openness to outcomes; collective responsibility and shared leadership were also identified as enablers of successful co- production. The volunteer and open access involvement allowed people to enter and leave the event at will. This is critical in social innovation events aiming to increase and accelerate citizen involvement. The openness to an outcome element concerns flexibility, acceptance of emerging ideas, and constant co-production. In this case the original idea about the social and co-created public park with minor funding was kept in mind and respected by the organisers, which in principle guided the co-production and the implementation of the park. Within this frame, the openness to the outcome (in the form of the appearance and content of the Sunshine PopUp Park) remained in place throughout the social innovation. The implementation of ideas included some selection in terms of the scope and of the ideas and the feasibility of implementing them. In addition, collective responsibility and 
shared leadership were related to volunteer involvement. Moreover, the interdependence of actors was also evident in our case, but played a minor role because the Sunshine PopUp Park was run by various small groups and inspired by others' contributions. Accordingly, our findings diverge from the past research that found examples of interdependence facilitating collaboration and impacting shared performance (Hackman, 2002; Wageman 1995; Wageman \& Gordin, 2005). It seems likely that the level of interdependence varies depending on the types of co-production. Specifically, in encouraging active citizenship and self-organising among citizens in social participation, the level of interdependence may be low at the beginning of the co-production and grow during the process of co-production and self-organising as citizens start to build shared goals and co-produce them.

Although the interdependence between open access and social innovation is complex and may have a different role in performance, interdependence (Wageman \& Gordon, 2005) may occur. In the Sunshine PopUp Park case, we identified two channels that nurtured interdependence: social media and knowledge sharing via the on-site notebook. With regard to the conditions and enablers of successful co-production, our findings show that in an open public Living Lab where the citizens are not necessarily together all the time (new volunteers enter and other volunteers may leave the event at any time during the process) the communication, coordination, and co-production is not only a face-to-face interaction, but is also mediated by social media (the Facebook group). The citizens could follow the course of the development/co-production process, contribute to ideation, and ask for and provide assistance. In this sense, the Facebook group offers a supporting and enabling social space, that is, a (social) infrastructure for successful co-production.

Another way to build interdependence is the use of various visualisations, such as the on-site notebook, which proved a suitable means through which to inform others of the house rules, about emerging problems, and to communicate other important issues. However, it is likely that in the short period of the Living Lab experiment an interdependence was established in smaller groups working on particular contributions on social innovation. Finally, the availability of facilitation and support often has a critical role in the emergence of co-production among volunteers. In this case, the encouragement to take action and implement ideas was provided by the organisers. As the nature of co-production is dependent on the dynamics and interaction of the people involved, the Living Lab kind of open access social innovation is composed of multiple, varied, smaller co-production performances.

Our interpretive sensemaking of the specific case study (Welch et al. 2011) did not intend for generalisation but for elaborating theory on citizens as active co-producers in social 
innovation by detailing their voluntary and active citizen involvement in innovation, coproduction and co-implementation. To conclude, this study contributes theoretically to the research on the co-production of social innovation between citizens and public-sector organisations. The concept of social innovation is becoming increasingly central to scientific and public discussions. Practitioners, policy makers, scholars and others increasingly agree on the merits of social innovations in addressing the significant challenges currently facing society and those that will face society in the future. Active citizenship, such as that described in this paper, has the potential to contribute to environmental, social, and institutional resilience in cities (Buijs, Mattijssen, Van der Jagt, Ambrose-Oji, Andersson, Elands \& Steen Møller, 2016).

This study has shown how to promote innovations that provide novel ways to capture opportunities or tackle problems that create collateral outcomes that ultimately benefit societal well-being. Social innovation is about social benefits and public good that supports people in organisations, communities, and society in general. We also documented a success case, the Sunshine PopUp Park, and we hope that similar experiments based on the lessons learned could emerge more broadly in society, so enabling self-organising and active citizenship in various contexts.

\section{References}

Baars, T. (2011). Experiential Science; Towards an Integration of Implicit and Reflected Practitioner-Expert Knowledge in the Scientific Development of Organic Farming. Journal of Agricultural \& Environmental Ethics, 24, 6, 601-628.

Buijs, A.E., Mattijssen, T.J.M. Van der Jagt, A.P.N., Ambrose-Oji, B., Andersson, E., Elands, B.H.M \& Steen Møller, M. (2016). Active citizenship for urban green infrastructure: fostering the diversity and dynamics of citizen contributions through mosaic governance. Current Opinion in Environmental Sustainability $22,1-6$.

Benari, E. (1990). A Bureaucrat in Every Japanese Kitchen?: On Cultural Assumptions and Coproduction. Administration \& Society, 21, 4): 472-492.

Brandsen, T., \& Honingh, M. (2015). Distinguishing different types of coproduction: A conceptual analysis based on the classical definitions. Public Administration Review, 76, 3, 427-435.

Cunningham, P., Herselman, M.E. \& Cunningham, M. (2012). Socio-economic impact of growing Living Labs and Living Lab networks into Africa. IST-Africa 2012 Conference Proceedings, Dar es Salaam, Tanzania.

Clary, E. G., Snyder, M., Ridge, R., Copeland, J., Stukas, A., Haugen, J. \& Miene, P. (1998). Understanding and assessing the motivations of volunteers: A functional approach. Journal of Personality and Social Psychology, 74, 1516-1530.

Clary, E. G., Snyder, M. \& Stukas, A. (1996). Volunteers' motivations: Findings from a national survey. Nonprofit and Voluntary Sector Quarterly, 25, 485-505.

Dawson, P. \& Daniel, L. (2010). Understanding social innovation: a provisional framework. 
International Journal of Technology Management, 51, 1, 9-21.

Dutilleul, B., Birrer, F. A., \& Mensink, W. (2010). Unpacking European living labs: analysing innovation's social dimensions. Central European Journal of Public Policy, 4, 1, 60-84.

Grant, A.M. (2008). Does intrinsic motivation fuel the prosocial fire? Motivational synergy in predicting persistence, performance, and productivity. Journal of Applied Psychology, 93, 1, 48-58.

Gray, B. (1989). Collaborating: Finding common ground for multiparty problems. California: Jossey-Bass Inc.

Gummesson, E. (2005). Qualitative research in marketing: Road-map for a wilderness of complexity and unpredictability. European Journal of Marketing, 39, 3/4, 309- 327.

Hackman, J. R. (2002). Leading Teams: Setting the Stage for Great Performances. Boston: HBS Press.

John-Steiner, V. (2006). Creative collaboration. Oxford: Oxford University Press.

Ketokivi, M., \& Choi, T. (2014). Renaissance of case research as a scientific method. Journal of Operations Management, 32, 5, 232-240.

King, N. (2004), Using templates in the thematic analysis of the text. In S. Cassel \& Symon, G. (Eds.), Guide to qualitative methods in organizational research (pp. 256270). Essential Sage Publications: London.

Leone, R., Walker, C., Curry, L., Agee, E. (2012). Application of a Marketing Concept to Patient-Centered Care: Co-Producing Health With Heart Failure Patients. OJIN: The Online Journal of Issues in Nursing, 17, 2.

Meijer, A. (2011). Networked Co-Production of Public Services in Virtual Communities: From a Government-Centric to a Community Approach to Public Service Support. Public Administration Review, 71, 4, 598-607.

Moulaert, F. and Mehmood, A. (2010). Spaces of social innovation. In A. Pike, A. Rodriguez-Pose, \& J. Tomaney (Eds.), A handbook of local and regional development (pp. 212-225). London: Routledge.

Osborne, S.P. (2018). From public service-dominant logic to public service logic: are public service organizations capable of co-production and value co-creation?, Public Management Review, 20:2, 225-231.

Ostrom, E. (1999). Crossing the great divide. Co-production, synergy \& development. Polycentric governance and development, In M.D. McGinnes, (Ed.), Reading from the workshop in political theory and policy analysis, Ann Arbor, MI: University of Michigan Press.

Prins, S. (2006). The psychodynamic perspective in organizational research: Making sense of the dynamics of direction setting in emergent collaborative processes. Journal of Occupational and Organizational Psychology, 79, 3, 335-355.

Sharp, E. (1979). Citizen Organizations and Participation in Law Enforcement Advocacy and Coproduction: The Role of Incentives. Ph.D. Dissertation. Chapel Hill, North Carolina: University of North Carolina at Chapel Hill, Department of Political Science.

Sawyer, R. K., \& DeZutter, S. (2009). Distributed creativity: How collective creations emerge from collaboration. Psychology of Aesthetics, Creativity, and the Arts, 3, 2, 81 92.

Stake, R. E. 2005. Qualitative case studies. In N. K. Denzin \& Y.S. Lincoln (Eds), Handbook of Qualitative Research, (3rd ed.) 443-466. Thousand Oaks, CA: Sage.

URBACT (2015). Social innovation in cities (2015). URBACT II Capitalization, URBACT https://urbact.eu/sites/default/files/03_socialinn-web.pdf [downloaded 17.6.2019] 
Wageman, R. (1995). Interdependence and group effectiveness. Administrative Science Quarterly, 40, 1, 145-180.

Wageman, R. \& Gordon, F.M. (2005). As the Twig Is Bent: How Group Values Shape Emergent Task Interdependence in Groups. Organization Science, 16, 6, 687-700.

Welch, C., Piekkari, R., Plakoyiannaki, E. \& Paavilainen-Mäntymäki, E. (2011). Theorising from case studies: Towards a pluralist future for international business research. Journal of International Business Studies, 42, 5, 740-762.

Voorberg, W. H., Bekkers V. \& Tummers L. (2015). A Systematic Review of Co-Creation and Co-Production: Embarking on the social innovation journey. Public Management Review, 17, 9, 1333-1357.

Voorberg, W., Bekkers, V., Timeus, K., Tonurist, P. \& Tummers, L. (2017). Changing public service delivery: learning in co-creation, Policy and Society. 36, 2, 178-194.

Voorberg, W., Jilke, S. Tummers, L. \& Bekkers, V. (2018). Financial rewards do not stimulate coproduction: evidence from two experiments. Public Administration Review, $78,6,864-873$

Wascher, E., Hebel, F., Schrot, K., Schultze, J. (2018): Social Innovation Labs - A starting point for social innovation, sfs/TU Dortmund University, Dortmund.

Wilson, J. (1973). Political organizations. New York: Basic Books. 
INDIVIDUAL CONDITIONS FOR CO-PRODUCTION...

Table 1.

Summary of the empirical results of the study according to the degree of involvement

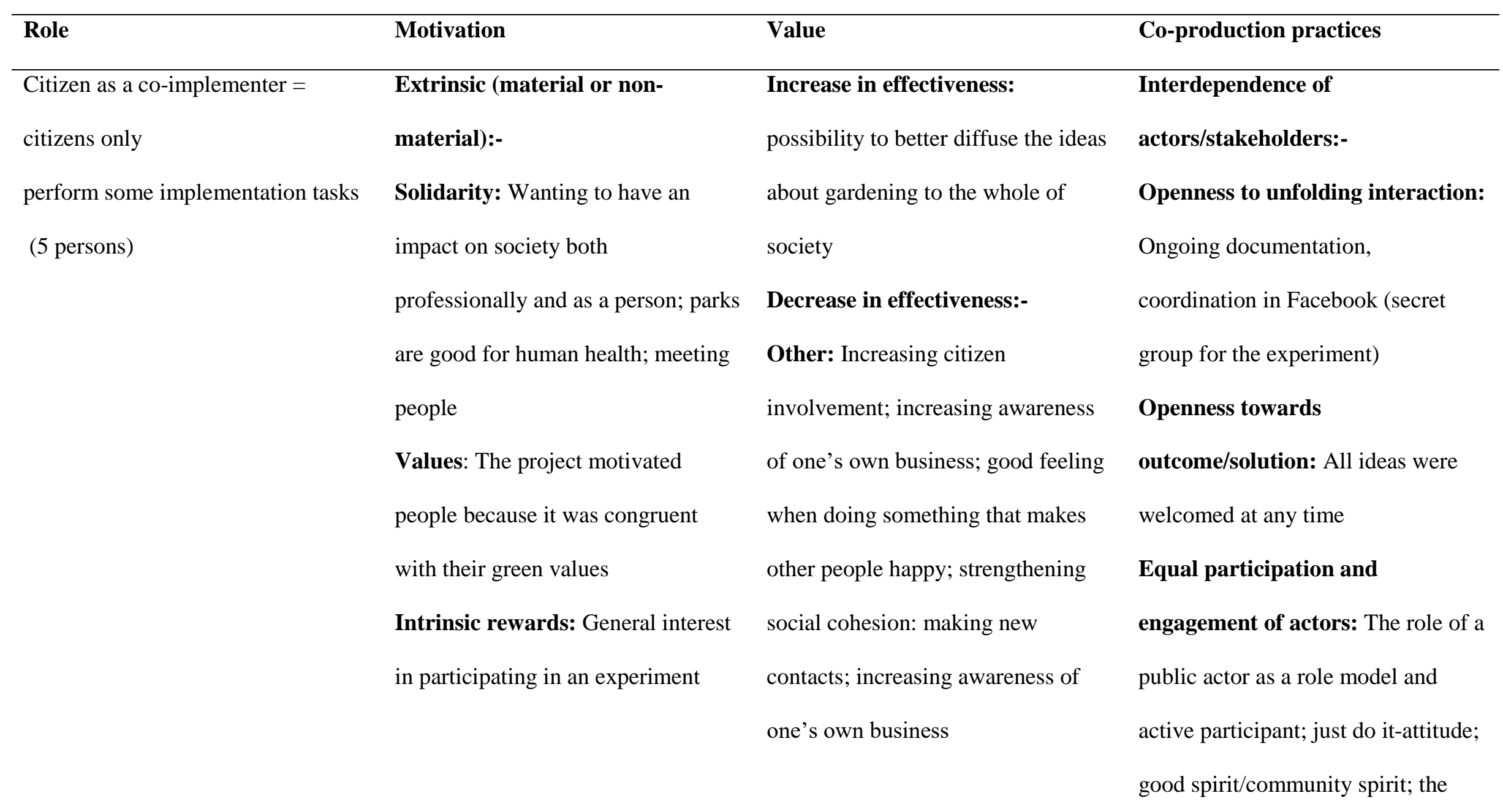




\section{Collective responsibility:}

Volunteering: the experiment is as good as the ideas of the volunteers and the implementation by the volunteers

\section{Shared leadership of the future}

direction of the event: The ideas provided by the volunteers created the direction of the experiment; experiment started from 'nothing'

Material rewards: Free coffee (not very significant)

Other: People who volunteered were open and easy going and easy 


\begin{tabular}{lll}
\hline Role & Motivation & Value \\
\end{tabular}

to get to know; common interest in

green/environmental issues

Citizen as a co-designer $=$ citizens

decide how the

activity is being designed

(2 persons)

\section{Extrinsic (material or non-}

material): Wanting to boost own

business; aspirations related to own

career,

Solidarity: Possibility to work with other people

Values: -

Intrinsic rewards: Wanting to see how public spaces could be used for this type of purpose
Increase in effectiveness: Finding

new contacts and potential

customers, new business

\section{Decrease in effectiveness:}

Other: Increasing awareness of one's own business; using the Sunshine PopUp Park for work purposes (meeting); enjoyment of

people's reactions related to

organising these types of things

voluntarily rather than relying on

any authorities

\section{Interdependence of}

actors/stakeholders: -

Openness to unfolding interaction:

Everybody was welcome to join the

experiment

\section{Openness to outcome/solution:}

\section{Equal participation and}

engagement of actors: The role of a public actor as a role model and active participant; volunteering

(unpaid)

Collective responsibility:- 


\begin{tabular}{|c|c|c|c|}
\hline Role & Motivation & Value & Co-production practices \\
\hline & & & $\begin{array}{l}\text { Shared leadership of the future } \\
\text { direction of the event:- }\end{array}$ \\
\hline Citizen initiator $=$ an initiative of & Extrinsic (material or non- & Increase in effectiveness: & Interdependence of \\
\hline citizens themselves & material) rewards: - & Decrease in effectiveness: & actors/stakeholders: \\
\hline \multirow[t]{10}{*}{ (1 person) } & Solidarity: - & Other: Feeling of achievement; & Openness to unfolding interaction: \\
\hline & Values: - & gaining a great deal of knowledge on & Openness to outcome/solution: \\
\hline & Intrinsic rewards: Realising one's & organising an experiment & Realising that everyone has good \\
\hline & own vision of the experiment and & & ideas (may not be easy for idea \\
\hline & seeing it come true & & owner, who has a clear vision) \\
\hline & & & Equal participation and \\
\hline & & & engagement of actors: \\
\hline & & & Collective responsibility: No \\
\hline & & & participants could complain about \\
\hline & & & the activities because they were \\
\hline
\end{tabular}




\begin{tabular}{|c|c|c|c|}
\hline Role & Motivation & Value & Co-production practices \\
\hline & & & $\begin{array}{l}\text { organising them themselves (and no } \\
\text { one was paid) } \\
\text { Shared leadership of the future } \\
\text { direction of the event:- }\end{array}$ \\
\hline $\begin{array}{l}\text { Public authority role } \\
\text { ( } 2 \text { persons) }\end{array}$ & $\begin{array}{l}\text { Extrinsic (material or non- } \\
\text { material) rewards: - } \\
\text { Solidarity:- } \\
\text { Values:- } \\
\text { Intrinsic rewards: Advancing } \\
\text { regional development plan }\end{array}$ & $\begin{array}{l}\text { Increase in effectiveness:- } \\
\text { Decrease in effectiveness:- } \\
\text { Other: Increasing citizen } \\
\text { involvement; realisation that there is } \\
\text { need for this type of place, } 11000 \\
\text { visits, over } 200 \text { ideas }\end{array}$ & $\begin{array}{l}\text { Interdependence of } \\
\text { actors/stakeholders: - } \\
\text { Openness to unfolding interaction: } \\
\text { Ongoing documentation in } \\
\text { Facebook; using a notebook for } \\
\text { daily notes and challenges; setting } \\
\text { house rules } \\
\text { Openness to outcome/solution: } \\
\text { Ensuring ideas and actions are } \\
\text { feasible; tolerating ambiguity }\end{array}$ \\
\hline
\end{tabular}


Equal participation and

engagement of actors: Involving

people in everything all the time,

being a role model and active

participant

Collective responsibility: Shared

leadership of the future direction of

the event

Other: Experiment had a beginning

and an end 